\title{
Microbial Oxidation of Alkyl Aryl Sulfides to the Corresponding Optically Active Sulfoxides ${ }^{\dagger}$
}

\author{
Hiromichi Oнta, * Yasushi Oкамото \\ and Gen-ichi TsuchiHashi \\ Department of Chemistry, Faculty of Science and Technology, Keio University, \\ Hiyoshi 3-14-1, Kohoku-ku, Yokohama 223, Japan
}

Received September 28, 1984

\begin{abstract}
Incubation of alkyl aryl sulfides with growing cells of Corynebacterium equi IFO 3730 afforded the corresponding sulfoxides and sulfones. The selectivity for the formation of sulfoxides over sulfones was higher with sulfides which have shorter alkyl chains. When methyl sulfides were used as substrates, formation of the corresponding sulfones was completely suppressed. Sulfoxides were revealed to have $87 \sim 100 \%$ optical purities as to the $(R)$ absolute configuration by HPLC analysis. The culture conditions seriously influenced the yield of oxidation products. High conversion of sulfides was attained when the reaction was carried out with growing cells in the logarithmic phase, in medium containing hexadecane as the carbon and energy source.
\end{abstract}

Sulfones and sulfoxides are very important compounds in organic chemistry, sulfoxides being especially useful synthons for asymmetric synthesis because of their chirality. ${ }^{1}$ Although, sulfoxides with high optical purities can be obtained via preparation and diastereomeric separation of l-menthyl sulfinates, ${ }^{2)}$ direct asymmetric oxidation of sulfides to sulfoxides has shown limited success. ${ }^{3}$ Very recently, Kagan et al. demonstrated that Sharpless's reagent ${ }^{4)}$ is useful for obtaining chiral sulfoxides from the corresponding sulfides, but the applicability is rather limited. ${ }^{5)}$ On the other hand, oxidation of sulfides utilizing biochemical systems provides another effective method for preparing chiral sulfoxides. ${ }^{6,7)}$ Although some efficient examples have reported, it is difficult to expect wide applicabilities for the so far known enzyme systems, because enzymes have their own substrate specificities. Thus, further development using new microorganism is desirable.

In the course of our studies on microbial transformation of organic molecules, we have found that Corynebacterium equi IFO 3730 has an enzyme system for oxidizing alkyl aryl sulfides, and it can be applied for synthesis of optically active sulfoxide. ${ }^{8)}$

\section{MATERIALS AND METHODS}

Spectroscopic measurement. The same instruments were used as described before. ${ }^{9)}$

Microorganism. Corynebacterium equi IFO 3730 was used throughout this study.

Media. The compositions of the media were as follows: (a) Inorganic medium: the basal medium reported before ${ }^{9)}$ supplemented with hexadecane, $1 \mathrm{ml}$ in $50 \mathrm{ml}$ of the medium, $\mathrm{pH}$ 7.2. (b) Yeast-meat juice medium: yeast extract, $5 \mathrm{~g}$; and meat extract $20 \mathrm{~g}$, in 1 liter of distilled water, $\mathrm{pH}$ 7.2. (c) Glucose medium: glucose, $4 \mathrm{~g} ; \mathrm{Na}_{2} \mathrm{HPO}_{4}, 7 \mathrm{~g}$; $\mathrm{NH}_{4} \mathrm{Cl}, 1 \mathrm{~g} ; \mathrm{KH}_{2} \mathrm{PO}_{4}, 3 \mathrm{~g} ; \mathrm{NaCl}, 0.5 \mathrm{~g} ; \mathrm{MgSO}_{4} \cdot 7 \mathrm{H}_{2} \mathrm{O}$, $0.5 \mathrm{~g}$; and $\mathrm{CaCl}_{2}, 10 \mathrm{mg}$, in distilled water, $\mathrm{pH} 7.2$.

Seed culture. A loopful of $C$. equi was inoculated into $50 \mathrm{ml}$ of the specified medium in a $500-\mathrm{ml}$ Sakaguchi flask and shaken at $30^{\circ} \mathrm{C}$ for 3 days. This suspension was used as the seed culture for the oxidation of sulfides.

Oxidation of sulfides. To a 500-ml Sakaguchi flask were added 45 to $48 \mathrm{ml}$ of the sterilized medium, 0.1 to $0.2 \mathrm{ml}$ of

+ Studies on Enzymatic Oxidation of Sulfides. Part II. For Part I, see ref. 8.

* To whom correspondence should be addressed. 
Table I. Spectral Data of Sulfoxides Obtained on Microbial Oxidation of Sulfides

\begin{tabular}{clll}
\hline Sulfoxide & \multicolumn{1}{c}{ IR $\left(\mathrm{cm}^{-1}\right)$} & \multicolumn{1}{c}{ NMR $(\delta)$} & \multicolumn{1}{c}{ MS (rel. intensity) } \\
\hline PhSOC $_{10} \mathrm{H}_{21}$ & $2950,2850,1480$ & $0.83(\mathrm{t}, 3 \mathrm{H}, J=6)$ & $267\left(\mathrm{M}^{+}+1,3\right), 249(41)$, \\
& $1460,1440,1090$ & $1.2(\mathrm{~m}, 14 \mathrm{H})$ & $126(71), 85(22), 78$ \\
& $1070,1040,1000$ & $1.54(\mathrm{~m}, 2 \mathrm{H})$ & $(48), 77(25), 71(25)$, \\
& 750,690 & $2.72(\mathrm{t}, 2 \mathrm{H}, J=7.5)$ & $57(69), 55(41), 43$ \\
& & $7.50(\mathrm{~m}, 5 \mathrm{H})$ & $(100), 41(58)$ \\
$\mathrm{PhSOC}_{4} \mathrm{H}_{9}$ & $2900,2825,1470$ & $0.92(\mathrm{t}, 3 \mathrm{H}, J=6)$ & $182\left(\mathrm{M}^{+}, 13\right), 165(4)$, \\
& $1450,1430,1080$ & $1.51(\mathrm{~m}, 4 \mathrm{H})$ & $126(100), 110(12), 104$ \\
& $1020,980,740$ & $2.67(\mathrm{t}, 2 \mathrm{H}, J=6.3)$ & $(5), 97(4), 78(50)$, \\
& 680 & $7.48(\mathrm{~m}, 5 \mathrm{H})$ & $57(8), 51(10), 41$ \\
& & & $(17)$ \\
$\mathrm{PhSOCH}_{3}$ & $2925,1480,1440$ & $2.61(\mathrm{~s}, 3 \mathrm{H})$ & $140\left(\mathrm{M}^{+}, 89\right), 125(100)$, \\
& $1410,1090,1070$ & $7.43(\mathrm{~m}, 5 \mathrm{H})$ & $97(79), 77(66), 65$ \\
& $1040,1000,960$ & & $(21), 51(68), 50(30)$, \\
& 750,690 & & $45(16)$ \\
& $2900,2850,1490$ & $0.87(\mathrm{t}, 3 \mathrm{H})$ & $281\left(\mathrm{M}^{+}+1,44\right), 264(19)$, \\
& $1460,1380,1080$ & $1.26(\mathrm{~m}, 16 \mathrm{H})$ & $263(74), 140(100), 92$ \\
& $1040,1010,810$ & $2.27(\mathrm{~s}, 3 \mathrm{H})$ & $(14), 91(9), 57(9)$, \\
& 720 & $2.77(\mathrm{t}, 2 \mathrm{H}, J=6.6)$ & $43(15)$ \\
& & $7.11(\mathrm{quart}, 4 \mathrm{H}, J=7.8)$ & \\
& $2960,2930,2870$ & $0.89(\mathrm{t}, 3 \mathrm{H})$ & $180\left(\mathrm{M}^{+}, 62\right), 137(30)$, \\
& $1.45(\mathrm{~m}, 4 \mathrm{H})$ & $124(100), 91(70)$, \\
& $1720,1500,1460$ & $2.36(\mathrm{~s}, 3 \mathrm{H})$ & $79(13), 77(16), 65$ \\
& $1400,1090,1030$ & $2.68(\mathrm{t}, 2 \mathrm{H}, J=6.9)$ & $(10), 45(29), 41(20)$, \\
& 1010,810 & $7.38(\mathrm{quart}, 4 \mathrm{H}, J=8.4)$ & $39(17)$ \\
& & $2.33(\mathrm{~s}, 3 \mathrm{H})$ & $154\left(\mathrm{M}^{+}, 60\right), 139(100)$, \\
& & $2.60(\mathrm{~s}, 3 \mathrm{H})$ & $111(11), 91(27), 65$ \\
& & & $(20), 63(12), 51(5)$, \\
& $3000,2920,1600$ & $45(7), 39(12)$ \\
& $1490,1450,1410$ & &
\end{tabular}

sulfides, and 5 to $2 \mathrm{ml}$ of the seed culture. Each whole mixture was incubated for 3 days at $30^{\circ} \mathrm{C}$ on a reciprocatory shaker. The broth was extracted with a $50 \mathrm{ml}$ portion of ethyl acetate three times. The combined extracts were washed with brine, dried over anhydrous sodium sulfate and then concentrated under reduced pressure. The mixture was subjected to column chromatography on silica gel. When inorganic medium was used, unaffected hexadecane was recovered as a hexane eluent. Then sulfur containing compunds were obtained as fractions eluted with diethyl ether. Purification of sulfoxides was performed by centrifugal TLC (Harrison Research). Sulfoxides were identified by comparison of their IR, NMR and mass spectra with those of authentic racemic specimens (Table I).

Determination of the ratio of recovered sulfides and oxidation products. The case of decyl phenyl sulfide (1a) is representative. Decyl phenyl sulfide $(0.3 \mathrm{ml}, 270 \mathrm{mg}$, $1.08 \mathrm{mmol}$ ) was incubated with $C$. equi as described above and sulfur containing compounds were isolated as a diethyl ether eluent (total yield, $300 \mathrm{mg}, 100 \%$ ). The ratio of decyl phenyl sulfide (1a), slfoxide (2a) and sulfone (3a) was determined by calculating the integral value of the spectra due to aromatic protons shown in Fig. 1. The three peaks at $\delta$ 7.2, 7.5 and 7.9 are assigned as being due to five protons of sulfide 1a, combined five protons of sulfoxide 2a and meta-, para-protons of sulfone 3a, and two orthoprotons of sulfone $\mathbf{3 a}$, respectively. Thus, it is possible to calculate the molar ratio of the three compounds from the integral ratio.

Determination of the optical purities of sulfoxides. Sulfoxides (2) were extracted from the culture broth and purified by column chromatography and centrifugal TLC. The ratio of two enantiomers was determined by HPLC (Shimadzu LC-5A). A Pirkle column ${ }^{10)}$ (prepared from a Toyo Soda TSK gel $\mathrm{NH}_{2}-60$ pre-packed column) and a Daicel chiral cell OA column were used. The analytical conditions and retention times are summarized in Table II.

Preparation of sulfides. Alkyl aryl sulfide were prepared by reaction of sodium arenethiolates with alkyl bromides in ethanol at room temperature. ${ }^{11)}$ More conveniently, a two phase system consisting of benzene, $2 \mathrm{~N}$ aqueous $\mathrm{NaOH}$ and a catalytic amount of cetyltrimethylammonium bromide was employed. ${ }^{12)}$ 


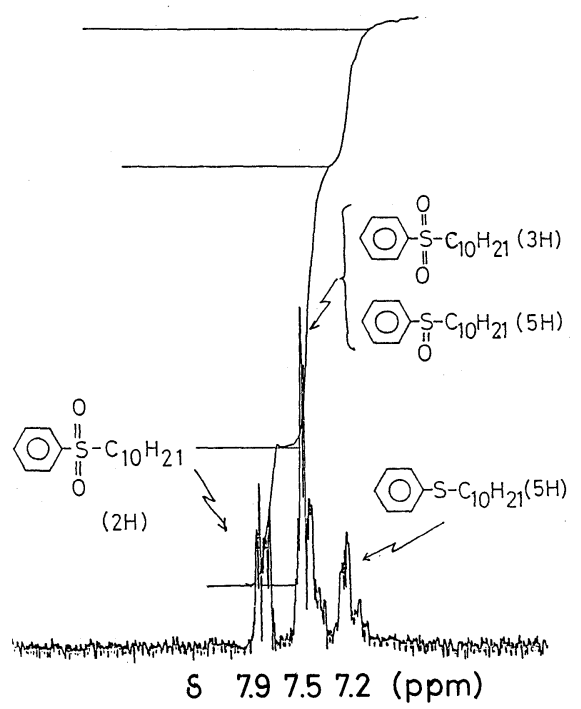

FIG. 1. NMR Spectrum due to Aromatic Protons of a Mixture of Decyl Phenyl Sulfide, Sulfoxide and Sulfone.

TABle II. HPLC ANAlysis of $(R)$ - AND $(S)$-SULFOXIDES

\begin{tabular}{lcc}
\hline \multirow{2}{*}{ Sulfoxide } & \multicolumn{2}{c}{ Retention time (min) } \\
\cline { 2 - 3 } & \multicolumn{1}{c}{$S$} & $R$ \\
\hline PhSOC $_{10} \mathrm{H}_{21}$ & 13.8 & $14.9^{a}$ \\
$\mathrm{PhSOC}_{4} \mathrm{H}_{9}$ & 17.7 & $18.9^{a}$ \\
$\mathrm{PhSOCH}_{3}$ & 25.2 & $23.0^{b}$ \\
$p-\mathrm{TolSOC}_{10} \mathrm{H}_{21}$ & 9.9 & $10.9^{c}$ \\
$p-\mathrm{TolSOC}_{4} \mathrm{H}_{9}$ & 12.6 & $13.7^{c}$ \\
$p-\mathrm{TolSOCH}_{3}$ & 22.3 & $19.3^{b}$ \\
\hline
\end{tabular}

a Pirkle column, solvent; hexane-isopropanol $(90: 10), 1 \mathrm{ml} / \mathrm{min}$.

b OA column, solvent; hexane-isopropanol (90:10), $0.5 \mathrm{ml} / \mathrm{min}$.

c Pirkle column, solvent; hexane-isopropanol (85:15), $1 \mathrm{ml} / \mathrm{min}$.

Preparation of authentic dl-sulfoxides and sulfones. Authentic $d l$-sulfoxides were prepared by oxidation of the corresponding sulfides with $35 \%$ aqueous hydrogen peroxide at $0^{\circ} \mathrm{C}$ to room temperature. ${ }^{13)}$ Sulfones were obtained by heating a mixture of a sulfide and a 3 molar equivalent of aqueous hydrogen peroxide in acetic acid for $3 \mathrm{hr}^{14)}$

Preparation of optically active decyl p-tolyl sulfoxide (2d). $l$-Menthol and $p$-toluenesulfinyl chloride were reacted in pyridine. Recrystallization of the reaction products from acetone gave $l$-menthyl- $(-)-(S)$ - $p$-toluenesulfinate. ${ }^{15)} \mathrm{mp} 103 \sim 105^{\circ} \mathrm{C}$. $[\alpha]_{\mathrm{D}}^{20}-200^{\circ}(c=2.08$, acetone $)$.

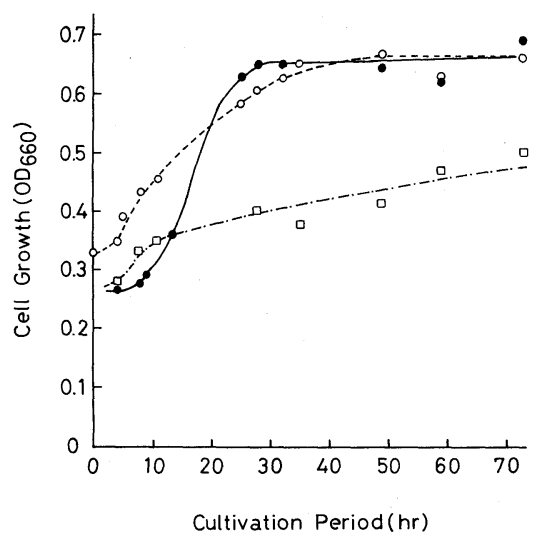

FIG. 2. Time Course of Cell Growth.

Cultivation was carried out at $30^{\circ} \mathrm{C}$ in medium (a). without sulfide; $\bigcirc$, with $0.4 \%$ of decyl phenyl sulfide; $\square$, with $0.2 \%$ of methyl phenyl sulfide.

Reaction of this $l$-menthyl ester with decylmagnesium bromide in benzene gave $(+)-(R)$-decyl $p$-tolyl sulfoxide. $^{16)} \mathrm{mp} 41 \sim 42^{\circ} \mathrm{C}$. $[\alpha]_{\mathrm{D}}{ }^{20}+140^{\circ}(c=1.47$, ethanol). NMR, IR and mass spectra were identical with those of the authentic racemic specimen.

Chemicals. Organic and inorganic chemicals were purchased from Tokyo Kasei Co., Wako Pure Chemical Industries and Kanto Chemicals. Chemicals for preparing the media were the products of Kyokuto Seiyaku Kogyo.

\section{RESULTS AND DISCUSSION}

The effect of the medium on the oxidation of decyl phenyl sulfide

As C. equi IFO 3730 has been demonstrated to have an affinity for substrates with long alkyl chains in the oxidation of 1 -alkenes ${ }^{17}$ and sec-alcohols, ${ }^{91}$ we expected that this microorganism would oxidize sulfur containing substrates with an analogous structure as well. Thus, oxidation of decyl phenyl sulfide (1a) was investigated.

The oxidation was carried out in the inorganic medium containing hexadecane as the carbon source. The substrate $(\mathbf{1 a}, 0.4 \%)$ and the seed culture were added to the medium at the same time and cultivation was carried out at $30^{\circ} \mathrm{C}$ for 3 days. The bacterium grew well, though the time required to reach the stationary phase was a little longer than in the case without the sulfide (Fig. 2). ${ }^{18)}$ NMR 
Table III. Effect of the Medium on the Oxidation of Decyl Phenyl Sulfide by C. equi ${ }^{a}$

\begin{tabular}{|c|c|c|c|}
\hline Medium & $\begin{array}{c}\text { Sulfone }^{b} \\
\left(\mathrm{~mol}^{\circ} \%\right)\end{array}$ & $\begin{array}{c}\text { Sulfoxide }^{b} \\
\left(\mathrm{~mol}_{\%}^{\circ}\right)\end{array}$ & $\begin{array}{l}\text { Sulfide }^{b} \\
\left(\mathrm{~mol}^{\mathrm{o}} \%\right)\end{array}$ \\
\hline Hexadecane & 48 & 18 & 34 \\
\hline Yeast-meat extract & 0 & 17 & 83 \\
\hline Glucose & 0 & 3 & 97 \\
\hline Phosphate buffer ${ }^{c}$ & 0 & 0 & 100 \\
\hline
\end{tabular}

a Cultivation was carried out at $30^{\circ} \mathrm{C}$ in Sakaguchi flasks containing $50 \mathrm{ml}$ of the medium and $0.2 \mathrm{ml}$ of decyl phenyl sulfide (1a). The substrate was added at the time of inoculation.

$b$ Determined by NMR.

c The bacterium grown in the yeast extract-meat juice medium was harvested, and suspended in the buffer of $\mathrm{pH} 7.2$.

analysis of the organic extract of the broth showed the formation of the corresponding sulfone (3a) and sulfoxide (2a) with consumption of the starting sulfide (Table III). The major product was decyl phenyl sulfone (3a).

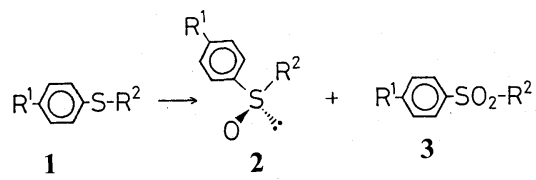

$\begin{array}{lll} & \mathrm{R}^{1} & \mathrm{R}^{2} \\ \text { a } & \mathrm{H} & \mathrm{C}_{10} \mathrm{H}_{21} \\ \text { b } & \mathrm{H} & \mathrm{C}_{4} \mathrm{H}_{9} \\ \text { c } & \mathrm{H} & \mathrm{CH}_{3} \\ \text { d } & \mathrm{CH}_{3} & \mathrm{C}_{10} \mathrm{H}_{21} \\ \text { e } & \mathrm{CH}_{3} & \mathrm{C}_{4} \mathrm{H}_{9} \\ \text { f } & \mathrm{CH}_{3} & \mathrm{CH}_{3}\end{array}$

It is interesting if the composition of the medium effects the activity of the enzyme system responsible for the oxidation of the sulfur atom. The results are summarized in Table III. It is clear that the oxidative activity is extremely suppressed in the nutrient medium and glucose medium. This can be accounted for by assuming that the enzyme system catalyzing oxidation of the sulfide and sulfoxide is profoundly concerned in the metabolism of hydrocarbons. Then, it can be presumed that the enzyme activity might vary depending on the growth phase. The oxidation reaction is expected to proceed quickly in the logarithmic phase, for the enzyme activity of oxidative degradation of hexadecane must be high in this stage. On the other hand, the oxidative ability will be low in the stationary phase, and as a result, conversion of sulfide 1 will be restricted to some extent. The results summarized in Table IV show that this hypothesis is actually valid. When sulfide 1a was added to the medium at the same time as inoculation of the seed culture, sulfoxide $\mathbf{2 a}$ and sulfone $\mathbf{3 a}$ were formed in good yields after 3 to 5 days. The fact that the conversion of $\mathbf{1 a}$ on 2-day cultivation reached a level comparable to that on 3 day cultivation indicates that most of the oxidation occurred in the first two days, i.e., in the logarithmic phase. On the other hand, when 1a was added 2 days after the inoculation, two-thirds of the starting material was recovered after subsequent 3-day cultivation. It is evident that the oxidative activity rapidly decreased with aging of the bacterium.

The $\mathrm{pH}$ of the medium also seriously affected the conversion of $\mathbf{1 a}$. The initial $\mathrm{pH}$ range in which $C$. equi oxidized the sulfide was narrow, i.e. from 6.5 to 8.0 .

As mentioned above, the preferable conditions for oxidation of sulfide 1a became clear, then this microbial oxidation was applied to some alkyl aryl sulfides.

\section{Oxidation of alkyl aryl sulfides with $C$. equi}

Straight chain alkyl phenyl and alkyl $p$-tolyl sulfides $(\mathbf{1 a} \sim \mathbf{f})$ were oxidized to the corresponding sulfoxides $(\mathbf{2 a} \sim \mathbf{f})$ and sulfones $(\mathbf{3 a} \sim \mathbf{f})$. On the other hand, isoamyl phenyl sulfide and decyl $o$-tolyl sulfide were entirely recovered on incubation with $C$. equi under the same conditons. This is considered to be due to steric hindrance around the reaction center.

Sulfides which have alkyl chains with large numbers of carbons tend to be oxidized smoothly. As can be seen from Table V, the proportion of a starting material recovered depends on its structure. When the concentration of sulfides was $0.2 \mathrm{ml} / 50 \mathrm{ml}$ of the medium, and the recovery of decyl phenyl sulfide was 
Table IV. The Effects of Precultivation Time on the Oxidation of Decyl Phenyl Sulfide ${ }^{a}$

\begin{tabular}{ccccc}
\hline $\begin{array}{c}\text { Precultivation } \\
\text { time (day) }\end{array}$ & $\begin{array}{c}\text { Cultivation } \\
\text { time (day) }\end{array}$ & $\begin{array}{c}\text { Sulfone }^{c} \\
\left(\mathrm{~mol}^{\circ}\right)\end{array}$ & $\begin{array}{c}\text { Sulfoxide }^{c} \\
(\mathrm{~mol} \%)\end{array}$ & $\begin{array}{c}\text { Sulfide }^{c} \\
\left(\mathrm{~mol}^{\circ}\right)\end{array}$ \\
\hline 0 & 2 & 49 & 15 & 36 \\
0 & 3 & 61 & 17 & 22 \\
0 & 5 & 78 & 10 & 12 \\
1 & 3 & 57 & 17 & 26 \\
2 & 7 & 16 & 17 & 67 \\
\hline
\end{tabular}

a Cultivation was carried out at $30^{\circ} \mathrm{C}$ in the inorganic medium containing hexadecane as the carbon source.

$b$ The period from inoculation of the seed culture to addition of sulfide $\mathbf{1 a}$.

c Determined by NMR.

Table V. Oxidation of Alkyl Aryl Sulfides with Corynebacterium equi IFO 3730

\begin{tabular}{|c|c|c|c|c|c|c|c|c|}
\hline & \multicolumn{2}{|c|}{ Substrate } & \multirow{2}{*}{$\begin{array}{c}\text { Concentration }^{a} \\
(\mathrm{ml})\end{array}$} & \multicolumn{3}{|c|}{ Molar ratio $(\%)$} & \multirow{2}{*}[\alpha]{$_{\mathrm{D}}$ of $\mathbf{2}^{b}$} & \multirow{2}{*}{$\begin{array}{c}\text { Optical } \\
\text { purity } \\
(\% /)^{c}\end{array}$} \\
\hline & $\mathrm{R}^{1}$ & $\mathrm{R}^{2}$ & & Sulfone 3 & Sulfoxide 2 & Sulfide 1 & & \\
\hline \multirow[t]{2}{*}{$\mathbf{a}$} & $\mathrm{H}$ & $\mathrm{C}_{10} \mathrm{H}_{21}$ & 0.2 & 48 & 18 & 34 & $+140^{\circ}$ & 98 \\
\hline & & & 0.1 & 88 & 7 & 5 & & \\
\hline \multirow[t]{2}{*}{$\mathbf{b}$} & $\mathrm{H}$ & $\mathrm{C}_{4} \mathrm{H}_{9}$ & 0.2 & 0 & 29 & 71 & $+193^{\circ}$ & 100 \\
\hline & & & 0.1 & 19 & 81 & 0 & & \\
\hline c & $\mathrm{H}$ & $\mathrm{CH}_{3}$ & 0.1 & 0 & 100 & 0 & $+106^{\circ}$ & 92 \\
\hline d & $\mathrm{Me}$ & $\mathrm{C}_{10} \mathrm{H}_{21}$ & 0.2 & 10 & 55 & 35 & $+124^{\circ}$ & 91 \\
\hline e & $\mathrm{Me}$ & $\mathrm{C}_{4} \mathrm{H}_{9}$ & 0.1 & 3 & 79 & 19 & $+164^{\circ}$ & 87 \\
\hline f & $\mathrm{Me}$ & $\mathrm{CH}_{3}$ & 0.1 & 0 & 33 & 67 & $+138^{\circ}$ & 97 \\
\hline
\end{tabular}

a Sulfide added to $50 \mathrm{ml}$ of the medium.

$b$ Measured in acetone.

c Determined by HPLC.

$34 \%, 71 \%$ of butyl phenyl sulfide was recovered unreacted. These tendencies were also confirmed when the yields of decyl sulfones were compared with those of butyl and methyl sulfones. The formation of sulfones decreased according to the decrease in carbon number. The reaction of aryl methyl sulfides is most demonstrative. In this case, the formation of sulfones was completely suppressed and only sulfoxides were obtained selectively, although a considerable amount of the starting material was recovered. This selectivity, together with the high enantio purities of the resulting sulfoxides, will be synthetically very favorable.

A methyl group at the para-position of the phenyl group also seems to have some effect on the course of the reaction. If one compares the molar ratios of sulfoxides to sulfones resulting from aryl sulfides which have the same alkyl group, it is clear that the para-methyl group is favorable for the accumulation of sulfoxides. One possible way of explaining this is to consider the electronic effect of the methyl group ${ }^{7)}$ and to assume that the oxidation of the sulfoxides occur through the nucleophilic attack of some active oxidizing species. As the paramethyl group is an electron releasing one, it will compensate for the positive charge on the sulfur atom of the sulfoxide group. Accordingly, $p$-tolyl sulfoxides are more deactivated than phenyl sulfoxide on the nucleophilic attack of oxidizing species, which will result in higher selectivity for sulfoxides over sulfones. Other explanations such as steric effects should not be neglected at present, this difference in reactivity is interesting and ex- 
pected to be useful.

\section{Stereochemistry}

All the sulfoxides obtained in this experiment were optically active and exhibited positive specific rotations, indicating that they have the $(R)$ absolute configuration around the sulfur atom. ${ }^{19)}$ As optically active decyl phenyl and decyl $p$-tolyl sulfoxide (2a and 2d) have not been reported, optically active $(R)$ decyl $p$-tolyl sulfoxide was prepared to confirm the absolute configuration of the microbial oxidation products. $l$-Menthyl- $(-)-(S)-p$-toluenesulfinate was prepared according to the reported procedures. ${ }^{16)}$ Reaction of alkyl Grignard reagents with this sulfinate ester has been shown to give $(R)$-alkyl tolyl sulfoxides with Walden inversion of the configuration on the sulfur atom. Decylmagnesium bromide gave the corresponding sulfoxide, which had the optical rotation with the same sign as the one obtained on microbial oxidation. Thus, it is concluded that the enzyme system of $C$. equi catalyzed the attack of oxidizing species from the pro- $R$ site of the sulfides regardless of the carbon number of the alkyl chain.

The optical purities of the sulfoxides were determined by HPLC and to be generally very high. Whether the small differences between the phenyl sulfoxide series and $p$-tolyl series are due to an electronic or steric effect is the problem for further studies.

In conclusion, microbial oxidation by $C$. equi has been developed as a facile method for obtaining alkyl aryl sulfoxides with a various numbers of carbon chain and of high optical purities.

\section{REFERENCES}

1) For example, G. Solladié, Synthesis, 185 (1981); Phosphorus and Sulfur, 2, 51 (1976); G. Posner, J. P. Mallamo, M. Hulce and L. L. Frye, J. Am. Chem. Soc., 104, 4180 (1982).

2) K. K. Andersen, Tetrahedron Lett., 93 (1962); J. Org. Chem., 29, 1953 (1964).

3) T. Sugimoto, T. Kokubo, J. Miyazaki, S. Tanimoto and M. Okano, J. Chem. Soc., Chem. Commun., 402 (1979); F. A. Davis, R. Jenkins, Jr., S. Q. A. Rizvi and T. W. Panunto, J. Chem. Soc., Chem. Commun., 600 (1979); K. Ogura, M. Fujita and H. Iida, Tetrahedron Lett., 2233 (1980).

4) T. Katsuki and K. B. Sharpless, J. Am. Chem. Soc., 102, 5974 (1980); B. E. Rossiter, T. Katsuki and K. B. Sharpless, J. Am. Chem. Soc., 103, 464 (1981).

5) P. Pitchen and H. B. Kagan, Tetrahedron Lett., 25, 1049 (1984).

6) B. J. Auret, D. R. Boid, H. B. Henbest and S. Ross, J. Chem. Soc., C, 2371 (1968); E. Abushanab, D. Reed, F. Suzuki and C. J. Sih, Tetrahedron Lett., 3415 (1978); S. W. May and R. S. Phillips, J. Am. Chem. Soc., 102, 5981 (1980); T. Tanaka, M. Yamazaki, K. Fujimori, Y. H. Kim, S. Oae and T. Iyanagi, Chem. Lett., 1441 (1980); Y. Watanabe, T. Numata, T. Iyanagi, and S. Oae, Bull. Chem. Soc. Jpn., 54, 1163 (1981); D. R. Light, D. J. Waxman and C. Walsh, Biochemistry, 21, 2490 (1982); D. J. Waxman, D. R. Light and C. Walsh, Biochemistry, 21, 2499 (1982); B. J. Auret, D. R. Boyd, E. S. Cassidy, F. Turley, A. F. Drake and S. Mason, J. Chem. Soc., Chem. Commun., 282 (1983).

7) Y. Watanabe, T. Iyanagi and S. Oae, Tetrahedron Lett., 21, 3685 (1980); Tetrahedron Lett., 23, 533 (1982); Y. Watanabe, S. Oae and T. Iyanagi, Bull. Chem. Soc. Jpn., 55, 188 (1982).

8) H. Ohta, Y. Okamoto, and G. Tsuchihashi, Chem Lett., 205 (1984).

9) H. Ohta, H. Fujiwara and G. Tsuchihashi, Agric. Biol. Chem., 48, 1509 (1984); and the references cited theirein.

10) W. H. Pirkle, J. M. Finn, J. L. Schreiner and B. L. Hamper, J. Am. Chem. Soc., 103, 3964 (1981); W. H. Pirkle, D. W. House and J. M. Finn, J. Chromatogr., 192, 143 (1980).

11) W. E. Parham and S. H. Groen, J. Org. Chem., 30, 728 (1965).

12) D. Landini and F. Rolla, Synthesis, 565 (1974).

13) W. E. Parham and M. D. Bhavsar, J. Org. Chem., 28, 2686 (1963); K. Ogura and G. Tsuchihashi, Bull. Chem. Soc. Jpn., 45, 2203 (1972).

14) D. S. Tarbell and C. Weaver, J. Am. Chem. Soc., 63, 2939 (1941).

15) C. Mioskowski and G. Solladié, Tetrahedron, 36, 227 (1980).

16) J. Drabowicz, B. Bujnicki and M. Mikolajczyk, J. Org. Chem., 47, 3325 (1982).

17) H. Ohta and H. Tetsukawa, J. Chem. Soc., Chem. Commun., 849 (1978); Agric. Biol. Chem., 43, 2099 (1979).

18) T. Nakahara, K. Hisatsuka and H. Yamada, Hakko Kyokaishi (Japan), 26, 414 (1968), [C.A., 70, 2768t (1969)].

19) K. Mislow, M. M. Green, P. Laur, J. T. Melillo, T. Simmons and A. L. Terney, Jr., J. Am. Chem. Soc., 87, 1958 (1965). 